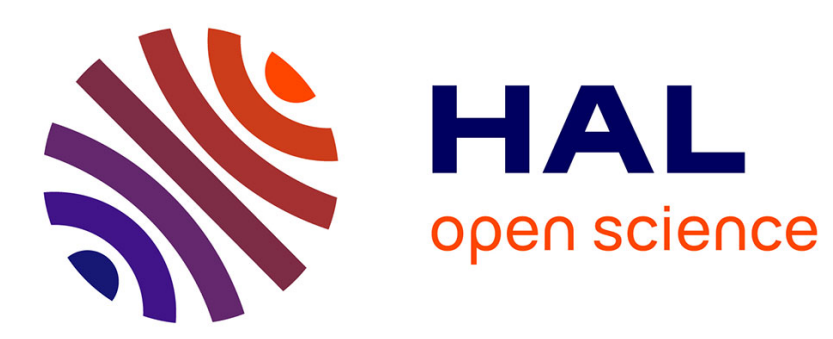

\title{
ReCollection: a Disposal/Formal Requirement-Based Tool to Support Collection Making
}

Francis Rousseaux, Alain Bonardi

\section{To cite this version:}

Francis Rousseaux, Alain Bonardi. ReCollection: a Disposal/Formal Requirement-Based Tool to Support Collection Making. 14th IEEE Mediterranean Electrotechnical Conference (MELECON'08)," May 2008, Ajaccio, France. pp.1-1. hal-01161040

\section{HAL Id: hal-01161040 \\ https://hal.science/hal-01161040}

Submitted on 8 Jun 2015

HAL is a multi-disciplinary open access archive for the deposit and dissemination of scientific research documents, whether they are published or not. The documents may come from teaching and research institutions in France or abroad, or from public or private research centers.
L'archive ouverte pluridisciplinaire HAL, est destinée au dépôt et à la diffusion de documents scientifiques de niveau recherche, publiés ou non, émanant des établissements d'enseignement et de recherche français ou étrangers, des laboratoires publics ou privés. 


\title{
ReCollection: a Disposal/Formal Requirement-Based Tool to Support Sustainable Collection Making
}

\author{
Francis Rousseaux and Alain Bonardi \\ IRCAM, Institut de Recherche et de Coordination Acoustique/Musique, \\ 1, place Igor-Stravinsky, \\ 75004 Paris - France \\ \{francis rousseaux, alain.bonardi\}@ircam.fr
}

\begin{abstract}
Modern Information Science deals with tasks which include classifying, searching and browsing large numbers of digital objects. The problem today is that our computerized tools are poorly adapted to our needs as they are often too formal: we illustrate this matter in the first section of this article with the example of multimedia collections. We then propose a software tool, ReCollection, for dealing with digital collections in a less formal and more sustainable manner. Finally, we explain how our software design is strongly backed up by both artistic and psychological knowledge concerning the ancient human activity of collecting, which we will see can be described as a metaphor for categorization in which two irreducible cognitive modes are at play: aspectual similarity and spatio-temporal proximity.
\end{abstract}

\section{MULTIMEDIA COLLECTIONS}

\section{A. Technological context}

Our modern WIMP-based interfaces were created in the early $70 \mathrm{~s}$, they were used on computers with low storage capacities, slow processing speed, relatively low connectivity and low resolution monitors. These computers were first used in offices and administrations, where the desktop metaphor fitted very well. Then, personal computers brought this kind of hardware to people's homes, and the desktop metaphor still fitted as computers were mainly used for editing and filing documents.

Since those times, the technology has leaped forward, and today a large portion of the population uses a computer and connects to the internet on a daily basis. Here in France ${ }^{1}, 9$ out of 10 people in the 18-24 age group use a computer and the internet daily. Computers are equipped with high storage capacity hard drives, powerful processors, high bandwidth internet connections, to name but a few technological trends. These are still evolving but the fact is that today more and more people are using their computers not only for editing and filing documents, but also for collecting music, films, images, books... Large amounts of these can be stored on hard drives and DVD-ROMS. The contents can be downloaded from the internet, or imported from digital devices such as cameras, which have also become mainstream.

Not surprisingly, a huge market has emerged from these multimedia collections. We can now choose from a myriad of

\footnotetext{
1 Les Français et l'ordinateur, phone survey by TNS SOFRES for the group Casino / L'Hémicycle, 15-16/04 2005
}

computerized tools which assist us in finding, retrieving, recording, creating, editing, browsing and classifying multimedia contents. The variety of tools at hand seems to fit with the variety of uses involved in multimedia computing, from the most creative ones - such as graphic design, audio synthesis, etc - to the most formal ones - classification in particular. However, there doesn't seem to be many tools bridging the gap between these two seemingly opposing polarities.

\section{B. Collecting: between formalism and creativity}

Let us illustrate this situation. First, let us suggest that looking for new material and classifying are two important processes involved in collecting. Indeed, when someone decides to start building a collection he usually already possesses a few items. Then, to extend this collection, new items must be added. In order to do so, the collector goes into the world and looks for these new items. Then as the collection builds up, the need to arrange the items into categories will become clearer, as the collection cannot simply remain a messy stack of unordered items.

So, in order to illustrate our point, let us describe a particular example: the music collector. As we have said, our collector will surely possess some initial items; these may be some CDs or vinyl records. His first action involved in extending his collection could be a visit to the record shop for example. Here, the music is classified conformingly to the record companies' desires, which can sometimes be confusing for our collector, who is a fan of Jimi Hendrix, and just does not know where to look for his albums: in the blues section? rock section? Is there a 'sixties' section? Anyway, despite finding them rather practical at first sight, our collector didn't create these labels, and finds it difficult adapting to them. However, as he browses through the shop, he also notices some nicely illustrated records, and discovers new artists he is interested in because their records are sitting next to Jimi's. Finally, when he has bought enough music records, and come back home, he will be able to start arranging his collection in a very personal and satisfying manner, which will be pleasing to the eyes, and also allow him to retrieve items quickly.

If he had decided to collect digital music, and go online to find new items for his collection, the process would have been rather similar. Commercial music download sites allow the user to browse through predefined music categories, thus implementing a kind of virtual record shop with the same 
problems mentioned earlier. The search tool however can come in handy, and allow the user to search for the name of an artist, a song, an album or even musical genre. All these are still editorial information, which aren't necessarily the most useful to the collector. Then, when the music is downloaded, the album consists of a group of compressed audio files, containing preset meta-tags, again storing editorial information. When browsing these files in his audio player, the songs are defined and classified automatically, not always according to the collector's desires. His final attempt is then to create a set of folders on his disk, and arrange his items in these folders. But how does he name these folders? What if he wants to arrange and browse the items in multiple ways? What if a particular item doesn't fit in any folder, or could be placed in two or three different categories? Pachet has also described many problems in the area of Electronic Music Distribution ([Pachet3]).

As we see from this example, the tools that the everyday user has at hand are too formal, and are poorly adapted to the growing activity of collecting multimedia contents. Indeed, what we have said for music can also be said for the other kinds of media, and can also be said for information research, file sharing, etc.

Attempts have been made at putting the human user back in control of the collecting process, rather than relying purely on predefined categories and automated research algorithms. However, it has become obvious that the other extreme of handing complete control over to the user isn't optimal either. Let us take a look at online content sharing sites, such as the famous FlickR ${ }^{\mathrm{TM}}$. There is no categorization here, but there are three main strategies when looking for photos: date, location, tags. The first two are self-explanatory, but the tags are more interesting here. When someone uploads a photo to the website, they can link a certain number of keywords, called tags, to this photo. Then, we can either browse through the most popular tags, or type a tag into a textbox for a more precise search. The users then have complete freedom on the way they choose to define their photos. But the problem is that many photos aren't tagged, and the photos that are, often have poorly named tags, making them difficult to retrieve. Therefore, we believe that an optimal solution to the problem of digital collections could lie somewhere between these two polarities: predefined categories and total user creativity.

\section{Examples of tools attempting to bridge the gap}

MusicBrowser is a software which aims at indexing large and unknown music collections, and also helping the user find "interesting" music in these collections ([Pachet4]).

When digital sound files are imported into the system, they are analyzed, and a database of their acoustic properties is created / updated. Then the user can browse through the collection in a traditional manner, relying on editorial information. He can also create his own categories intuitively. He starts by creating a category, and giving it a name. This can be totally subjective if he wishes, he may call it "evening music", "happy music" or "favorite", etc. He then adds a few songs to this category, before asking the program to finish classifying, based on acoustic similarities. Of course, the more categories there are, and the more examples there are, the easier it is for the system to classify the entire collection. However, if there are mistakes, the user may simply move a song from one category to another, and ask the system to start again. This creative feedback loop, between user input and automated algorithms, will eventually lead to a satisfying classification for the user, who will have saved a lot of time in the process. He will then be able to create other classifications of the same collection if he wishes, and switch instantly between any of them. He may also share these classifications or download others.

IMEDIA is a research project focused on indexing large collections of photos, and interactive searching and browsing ([Boujemaa]). When photos are added to the system, they are analyzed and a database of visual descriptors is created / updated. One of the main features of the program is allowing the user to search for similar photos. At first, a list of random images from the collection is displayed, the user may browse them, or view another set of random images. When he sees a photo he likes, he can select it and ask the system to find similar ones. For example, if he chooses a photo of a beach, then the system will display a list of photos of beaches. Once again, if the user isn't completely satisfied with the results, a "relevance feedback" system allows him to select the errors, and the system will take this into account in order to display a more relevant list of results.

In these two systems, we have noticed a creative feedback loop between the human user's input (starting point, examples, relevance feedback...) and the computer (automated algorithms for classifying and searching). This helps the user build and browse his collection in a constructive process, leading to a result which neither he nor the computer could have achieved alone. Also, both editorial information and semantic information (invisible to the user) are taken into account. IMEDIA and MusicBrowser address the problems of music collections, and photo collections, but the same ideas may be applied to other media collections, such as texts or videos, for example. It is only a case of finding the appropriate descriptors. Also, both these ideas, interactive searching and browsing, can be transposed to different media.

We can even think further, and imagine a common environment for collecting multimedia files. This could be a system with a generic layout and set of functionalities that would give birth to different programs specialized in collecting certain types of media. In the next section, we shall present a software prototype that we have implemented in order to experiment with this idea. As we shall see in the next section, we have tried to create a program more suitable to the particular process of collecting, which has an element of subjectivity, evolves over time and doesn't rely purely on similarities, as in the IMEDIA system for example. Indeed, we sometimes wish to expand our collection with something completely different, now how would we do that? We also believe that this process lies somewhere between formal classification/automated algorithms and total creativity. There are more and more examples of this, such as the two projects described previously, and we will try to take this process even further.

\section{RECOLLECTION: AN EXPERIMENTAL SOFTWARE FOR THE CREATION OF MULTIMEDIA COLLECTIONS}

ReCollection is a computer program for searching, arranging and browsing digital content.

As our collecting activities vary from one context to another, it is too ambitious to seek a general solution to the 
problem. Rather, particular application areas must be defined and isolated, in order for a specific answer to be given, however always relying on a set of basic principles. Here, we shall discuss the software prototype we have created for the digital opera / open form opera Alma Sola ${ }^{2}$.

\section{A. A useful metaphor: the art collection}

Artists and philosophers have described some very particular characteristics of collections. One of those, as noted by Wajcman, is that of excess in a collection ([Wajcman]). This means that the number of collected items exceeds the collector's capacity of memorization, but also of physical storage and exposition in the gallery. Thus, there is a need for at least one reserve, where the excess can be stored. For example, the George Pompidou National Museum of Modern Art, Paris, owns about 59000 artworks, making it one of the largest modern and contemporary art collections in Europe. Obviously, all the items cannot be exposed in the galleries at once, so a very large portion is stored in the reserves. Often, the items in reserve are stored in heaps, in random locations, and they aren't always labeled, which makes it difficult to find and retrieve objects.

The reserve allows us to handle the excess in collections, which is a problem in many of today's computer applications. Our multimedia collections, for example, are becoming very large and we are often losing control over them.

On the other hand, objects which are currently exposed are found in the gallery. Here, the objects follow a spatio-temporal arrangement defining a finite number of visitation paths. The closeness in space of certain artworks and the chronological order in which they are approached are set carefully by the curator, as they strongly influence the visitors' experience. This aspect is also very important, and we shall discuss it later in detail.

\section{B. The reserve}

The ReCollection software has two main modes: reserve and gallery. The reserve allows us to store our objects which aren't exposed in the gallery. There are many objects in the reserve, and these are not always labeled; also they are rarely arranged in an orderly and tidy manner. So when we visit the reserve, we have no choice but to wander around, picking up objects, inspecting and identifying them one at a time. The reserve can also be compared to the attic, in which our family possessions are stored similarly. As we explore our attic, we can happen to pick up an old photo album, which we had completely forgotten about. This item will surely bring back memories and emotions. We can then choose to keep this album under our arm, as we continue to explore the attic, or we can leave straight away, and put it on our fireplace, for example, making it visible to visitors. It is all these pleasant and familiar experiences which we believe can be recreated thanks to the modeling of the reserve in our computer program.

\footnotetext{
2 Designed by Alain Bonardi, IRCAM, Paris and performed at Le Cube, Issy les Moulineaux, October 2005.
}

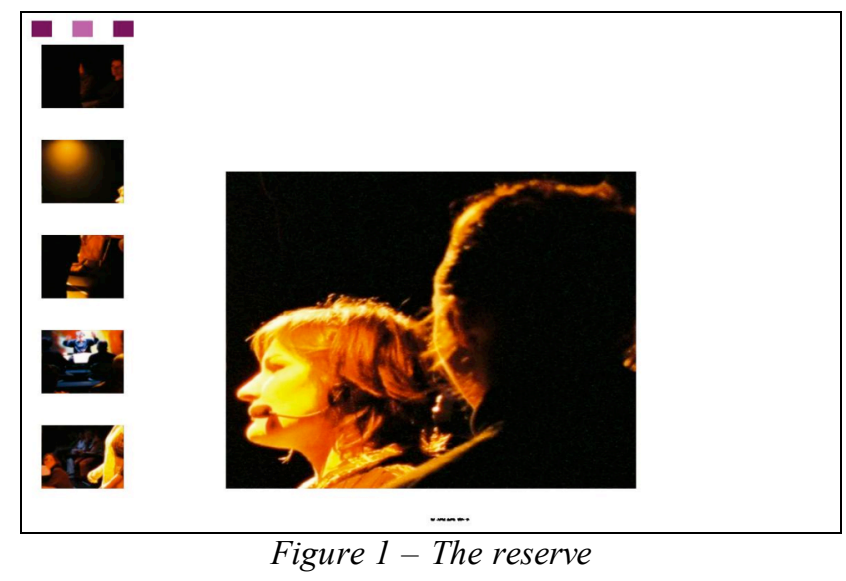

The user can create any number of reserves. However, he must create at least one, and store at least one object in this reserve. When he is in reserve mode, he can only view one object at a time. When he decides to view another object, it is chosen randomly from the remaining items in reserve. During a visit, each object is viewed only once. If the user wants to view an item he has already visited, he may go through the history of items on the left side of the screen, as shown in figure 2 . When he finds an object of interest, he can move it to the gallery. It will then be removed from the reserve, and saved in memory, with a group of objects waiting to be imported in the gallery. Then, in gallery mode, the user will see this heap of objects, and will be able to import it in the desired gallery, at the desired location.

\section{The objects}

The items in the Alma Sola collection are made up of three components:

- a photo of the performance,

- a sound recording of a few seconds of the singing,

- a text, the line which is sang in the corresponding sound file.

These are all regular files stored on disk (bitmap, wave and .txt formats). Each item also has a name. In a more general context, the objects can be made up of any one of these types of media, a video (though not implemented in this version), or any combination of these.

Also, each object has a set of descriptors attached. There is a specific set of descriptors for each type of media, which describe the contents of the object, for example the average volume of the sound, the brightness of the photo, the number of words, etc. Depending on the application, we could also include editorial information, such as date, author, etc.

These descriptors may be assimilated to the private properties of traditional computer objects. But in the context of collecting objects, we also need to account for other properties that come from the activities in which these objects collectively engage.

\section{The gallery}

A collective activity involving a number of objects at a time is their relative arrangement in the gallery space. To the location of objects in this space, we have added their color; these two properties make up an extra conceptual layer which 
is the framework for the creation and management of our collections.

In ReCollection, there is always at least one gallery, and the user can create as many as he wishes. There is always at least one item in a gallery, some basic content that the user can interact with, a starting point for his collection.

The objects can be placed and arranged manually in the gallery space, using click and move, just as in common user interfaces. The user can also rely on two algorithms to automatically dispose the objects. The first one, inspired by cataRT software ([Schwarz]), calculates the objects' positions and colors according to descriptors chosen by the user. The second calculates the positions depending on a sample of objects selected by the user. A Principal Components Analysis (PCA) finds out which descriptors vary most amongst the objects of the sample, the system can then rearrange the whole gallery according to these descriptors, as in the first method.

The arrangements resulting from the algorithmic calculations can always be modified manually in order to correct them (in the eventuality of rather subjective descriptors), to build up a global figure, or to bring items together. This way, through creative human-computer feedback loops, meaningful global figures can emerge through the arrangement in space of collected items, as well as local figures, soft pseudo-categories which are heaps of objects brought together by the system and/or the human user. These pseudo-categories are the building blocks for the classes the collection is implicitly aiming for. They are easily and constantly updated; items are added and removed instantly by being moved in space. They are loosely defined and never completely closed off from others, allowing some objects to be lost somewhere in between several heaps, when they cannot be placed in any one category. In a nutshell, this system allows for the creation of collections in which classes are in constant evolution, and are built by exploiting not only the objects' degree of similarity, but also their relative location in space and time.

Furthermore, the user may wish to search for objects in the gallery or in the reserve, in order to build on these categories, look for new kinds, or even fill in gaps in the gallery space. For this, the ReCollection system has two search tools he can use. The first is a simple 'keyword query', which searches for a keyword within the text or names of the objects. The second is a 'search by similarity'. The user selects an object, or group of objects, and the system searches for items which are similar (according to the descriptors). In both cases, the search is carried out in both the gallery and reserve, and a list of results is displayed in the gallery, ordered by similarity.

Once all the items of interest have been imported from the reserve, through browsing or searching, and once they have been arranged in the gallery space, the user has a first disposition he can play with. When he will browse the gallery space, his experience will be influenced by the fact that certain objects are close in space, and in time of visitation. Although this is interesting in itself, the system can help the user go further, by defining a set of guided visits, which are simply an order of visitation of selected objects in the gallery.

The type of interface we have chosen to implement these functionalities is a 2D zoomable user interface (ZUI), inspired by Ken Perlin's Pad ([Perlin]). All objects are in the same 2D space, which has no borders. The point of view can be moved vertically and horizontally, and the user can zoom in and out.
If he zooms in on an item, until it fills the screen, the sound is played back. This kind of interface has been experimented; it has obtained good results, and has been proven reliable ([Guiard]). Its intuitive approach is seducing to us, particularly in our goal of intuitively collecting digital media. Finally, the spatial metaphor takes advantage of the users' spatial memory and cognitive abilities ([Seegmiller], [Hasher]).

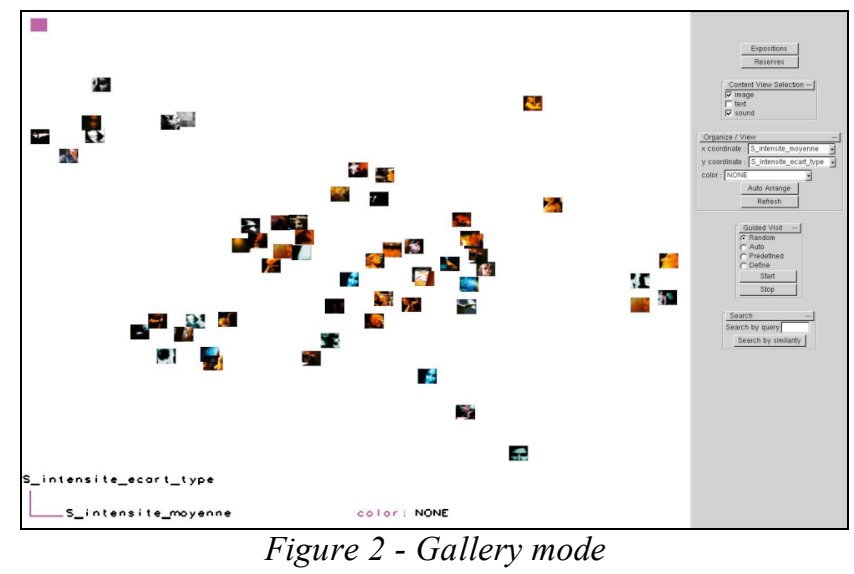

In the next part of this article, we shall discuss in detail some key characteristics of collections, as identified by artists, philosophers and psychologists. This theory is at the foundation of our work, and it demonstrates the novelty and usefulness of the collections metaphor in computer science.

\section{THE STRANGE STATUS OF COLLECTIONS}

Object-oriented computer science was invented to assist the task of classifying objects in a structure where different classes are distinguished ([Perrot], [Granger], [Baudrillard]).

As we all know, this innovation quickly became a success.

\section{A. Collections, between order and disorder}

Recently, an innovative trend is mobilizing computer objects for the organization of our collections, considered like a group of objects waiting to be organized in ad hoc classes that must be created simultaneously ([Pachet1], [Serra], [Rousseaux2]).

Because our collections seem to be nearer to order than disorder, attempting to assimilate them in classes is not so surprising. At least, collections look like they are waiting for their completion within a classification order, with the aim of turning into canonic achieved structures made of objects and classes. But something is also resisting this assimilation, as artists and philosophers have always noticed.

\section{B. Artists' fascination for collection regimes}

As a matter of fact, artists and philosophers have always been fascinated by the rebellious nature of collections and have demonstrated this in their own way ([Benjamin], [Wajcman], [Pomian], [Tourangeau]).

Here, for example, is the analysis of Gérard Wajcman (Catalog for the inaugural exhibit of the Maison Rouge) on the status of excess in a collection:

"Excess in a collection does not mean disordered accumulation; it is a fundamental principle: for a collection to 
exist as such-in the collector's eyes the number of objects must exceed the physical possibilities of exposing and storing the entire collection at home. Therefore, someone who lives in a studio can have a collection: it is only necessary for him to have at least one work he cannot hang in his studio. That is why the reserve is an integral part of collections. Excess also applies to the capacity of memorization: for the collection to exist, it is necessary for the collector not to be able to remember all the works he owns. In fact, the number of objects he owns must be so important that it becomes too important, so that the collector can forget one of them or leave a part of his collection outside of his home. To say it differently, for a collection to exist, the collector must not have full control over his collection anymore."

\section{COMPUTER SCIENTISTS AND COLLECTIONS}

Undoubtedly impressed by artists and philosophers who considered the strange status of collections, "object-oriented" computer program designers understood that computer modeling of object collections would necessarily involve the creation of hybrid structures including private characteristics by which the collected objects are usually referred to - but also including characteristics that come from the activities in which these objects collectively engage.

\section{A. A parsimonious, conservative, and seductive, approach}

Often, the approach implicitly chosen to characterize a collection is parsimonious and consists of over-determining the private referencing of the collected objects through a minimal description of the collective activity's context, even if it means predicting that the collection shall become a class or set of classes.

This practice presents the unquestionable advantage of not fundamentally opposing the traditional modeling of objects. However, it does not always live up to the collectors' high standards.

Here it is important to distinguish between figural and nonfigural collections. This subtle distinction, introduced in the 1970s by Piaget and his research teams of child psychologists ([Piaget \& Inhelder]), brings more light to the situation. If it is certain that (non-figural) collections that adapt well to the aforementioned parsimonious approach exist, it is because they are completely independent of their spatial configuration. In that, they are already close to classification, of which they can only envy the formal completeness. On the other hand, there are collections we can label as figural because both their arrangement in space and the private properties of the collected objects determine their meaning.

\section{B. Collections versus classes}

In their book La genèse des structures logiques élémentaires (lit: The Genesis of Elementary Logical Structures), Jean Piaget and Bärbel Inhelder provide a precise distinction between figural and non-figural collections, which are still called classes or categorical collections. For the authors, a class requires only two categories or relationships, both necessary and sufficient, for its actual definition as a class (page 25):
The qualities common to its members and to those of the classes it belongs to, as well as the specific differences that distinguish its own members from the members of other classes (comprehension);

The relationship of a part to the whole (membership and inclusion) determined by the quantifiers "all", "some" (including "one") and "none" applied to the members of the class in question and to other members of the classes it belongs to, defined as extensions of that class.

For example, cats share in common several qualities owned by all cats, some being specific and some others belonging also to other animals. But no spatial considerations ever enter into such a definition: cats may be grouped or not in the space without any change concerning their class definition and properties (1) and (2).

Piaget then introduces figural collections, in which meaning defined by properties (1) and (2) is linked to the spatial arrangement of its elements. A figural collection composes a figure, through the spatial relationships between its elements, whereas non-figural collections and classes are free of any figure.

\section{Figural versus non-figural collections}

It is precisely these figural collections that object-oriented computing is promising more and more an effective modeling of, pushed by an ever-growing social demand for on-line digital media browsing and information research amongst multiple sources ([Pédauque], [Rousseaux2]).

But as we now understand, figural collections adapt poorly to their assimilation into non-figural collections or classes. Although according to Piaget, collections are destined to become classes, in the same way as subjects will grow psychologically so as to improve their cognitive capacity to classify. Still referring to Piaget, it is a radical lack of differentiation that nudges figural collections out of the classical modeling field.

\section{CONCLUSION}

Husserl used to say that consciousness is always consciousness of something, that consciousness always predates the subject and the object, and puts them together in the process. There are no subjects or objects already existing independently that meet in the world to fill out a journal of experiences (the subject) and perhaps adapt to each other by induction. In the same fashion, we could say that a collection is always a collection of something, in that the original process of categorization is the activity of collecting, implacably mixing abstraction and spatio-temporal arrangements, and producing as many metastable categories.

The current models for information search are too formal, and they assume that the function and variables defining the categorization are known in advance. In practice, however, when searching for information, experimentation plays a good part in the activity, not due to technological limits, but because the searcher does not know all the parameters of the class he wants to create. He has hints, but these evolve as he sees the results of his search. The procedure is dynamic, but not totally random, and this is where the collection metaphor is interesting. 
The collector's experimentation is always carried out by placing objects in temporary and metastable space/time. Here, the intension of the future category has an extensive figure in space/time. And this system of extension (the figure) gives as many ideas as it does constraints. What is remarkable is that when we collect something, we always have the choice between two systems of constraints, irreducible one to the other. This artificial indifferentiation for similarity/contiguity is the only possible kind of freedom allowing us to categorize by experimentation.

Our prototype implements these ideas by allowing the user to dispose his objects in 2D space. This arrangement may be manual, automated or both; it may be based on similarity, spatial proximity or both. A global figure may emerge from this arrangement, influencing the browsing and also the extension of the collection. Local figures emerge, which are the temporary pseudo-classes illustrating the pre-categorization building process of collecting. The art gallery metaphor fits very well, as it adds further meaning to the arrangement of the collected items in space, and models the excess in collections thanks to the reserve.

Through exploiting space in this way, the software interface takes advantage of our cognitive abilities in dealing with spatial information, and also our ability to collect information and acquire knowledge. Our next step is experimentation in order to validate our work. This could simply take the form of a series of sessions in which both novice and experimented users are asked to build up collections using the software. Through user-feedback, we will have a first idea of how well the interface is understood, how useful the users find it and how easy it is to use. If this experiment is a success, as we believe it will be, we will continue our research and bring it to the next level. Through integrating new functionality focused on indifferentiation for similarity/proximity, we will be able to build specific tools for a variety of applications in which the user's activity may be - at least metaphorically - described as building a figural collection.

\section{REFERENCES}

\section{Books}

[1] [Baudrillard]. Jean Baudrillard, The System of Objects, Verso, 2005

[2] [Benjamin]. Walter Benjamin, Paris, capitale du XIX ${ }^{\mathrm{e}}$ siècle - le livre des passages, Le Cerf, 1989

[3] [Granger]. Gilles-Gaston Granger, Formes, opérations, objets, VRIN, 1994

[4] [Piaget \& Inhelder]. Jean Piaget, Bärbel Inhelder, La genèse des structures logiques élémentaires, Delachaux et Niestlé, 1980

[5] [Pomian]. Krzysztof Pomian, Collectionneurs, amateurs et curieux, Gallimard, 1987

[6] [Rousseaux1]. Francis Rousseaux, Singularités à l'œuvre, Collection Eidétique, Delatour, 2006

[7] [Wajcman]. Gérard Wajcman, Collection, Nous, 1999

Articles

[8] [Bonardi]. Alain Bonardi, New Approaches of Theatre and Opera Directly Inspired by Interactive Data-mining, Sound \& Music Computing Conference (SMC'04), pages 1-4, Paris, 20-22 October 2004

[9] [Boujemaa]. N. Boujemaa and C. Nastar, Content-based image retrieval at the imedia group of the inria. 10th DELOS Workshop Audio-Visual Digital Libraries Santorini, 1999.

[10] [Brézillon]. Patrick Brézillon, Context in Human-Machine Problem Solving: a Survey, Knowledge Engineering Review, 14, 1-34, 1999
[11] [Guiard] Guiard Y. Bourgeois F. Mottet D. Beaudoin-Lafon M., Beyond the 10-bit barrier : Fitts' law in multiscale electronic worlds. Proc. IHM-HCI 2001, Springer-Verlag, 2001.

[12] [Hasher] Hasher L. and Zacks R.T. Automatic and effortful processes in memory. Journal of Experimental Psychology, 1979.

[13] [Pachet1]. François Pachet, Les nouveaux enjeux de la réification, L'Objet, 10(4), 2004

[14] [Pachet2]. François Pachet, Nom de fichiers: LeNom, Revue du groupe de travail STP, Maison des Sciences de l'Homme Paris, 2004

[15] [Pachet3]. François Pachet, Content Management for Electronic Music Distribution: The Real Issues. Communications of the ACM, April 2003.

[16] [Pachet4]. Pachet, F., Aucouturier, J.-J., La Burthe, A., Zils, A. and Beurive, A. The Cuidado Music Browser : an end-to-end Electronic Music Distribution System. Multimedia Tools and Applications, 2006. Special Issue on the CBMI03 Conference

[17] [Perlin] Fox D. Perlin K. Pad : An alternative approach to the computer interface. Proc. ACM SIGRAPH'93, 1993

[18] [Perrot]. Jean-François Perrot, Objets, classes et héritage : définitions, dans «Langages et modèles à objets Etat des recherches et perspectives », collection Didactique, INRIA, pages 3-31, 1998

[19] [Rousseaux2]. Francis Rousseaux, La collection, un lieu privilégié pour penser ensemble singularité et synthèse, Revue électronique Espaces Temps, http://www.espacestemps.net/document1836.html, 2005

[20] [Rousseaux3]. Francis Rousseaux, Par delà les Connaissances inventées par les informaticiens : les Collections?, Intellectica, 2005/2$3, \mathrm{n}^{\circ} 41-42,2006$

[21] [Schwarz] Schwarz D. Beller G. Verbrugghe B. Britton S., Real-time corpus-based concatenative synthesis with catart. DAFx, 2006.

[22] [Seegmiller] Seegmiller D. Mandler J.M. and Day J., On the coding of spatial information. Memory and Cognition, 1977.

[23] [Serra]. Xavier Serra, Towards a Roadmap for the Research in Music Technology, ICMC 2005, Barcelona, September 2005

\section{Other references}

[24] [Pédauque]. Roger Pédauque (pseudo), http://rtpdoc.enssib.fr/rubrique.php3?id_rubrique $=13$

[25] [Peyret]. Jean-François Peyret, Trouver le temps, colloque Ecritures du Temps et de 1'Interaction, http://resonances2006.ircam.fr/?bio=57, Ircam, June 2006

[26] [Tourangeau]. Sylvie Tourangeau, Collection création, parcours désordonné, propos d'artistes sur la collection, http://collections.ic.gc.ca/parcours/laboratoire/livre/creation.html 